\title{
NILAI RELIGI DALAM NOVEL MENGEJAR HALALNYA SYABILA KARYA NOOR RUHAIMIN
}

\author{
Heppy Lismayanti, Haris Supratno, dan Tengsoe Tjahjono \\ Universitas Negeri Surabaya \\ Jalan Rektorat Unesa, Lidah Wetan, Kec. Lakarsantri, Suarabaya \\ email: heppy.19017@mhs.unesa.ac.id, harissupratno@unesa.ac.id, \\ tengsoetjahjono@unesa.ac.id
}

\begin{abstract}
This study examines the religious values contained in the novel Mengejar Halalnya Syabila by Noor Ruhaimin. The purpose of this study is to: (1) describe aqidah, (2) describe worship, and (3) describe morals in the novel Mengejar Halalnya Syabila by Noor Ruhaimin. The method in this research is descriptive analysis method. The data source in this study is the novel Mengejar Halalnya Syabila by Noor Ruhaimin. This novel was published by BanyuwangiNaa Publisher in 2018. The collection technique in this research is the text observation technique and the data analysis technique used is interpretive descriptive technique. Based on the research results obtained: Religious values associated with aqidah namely, (a) faith in God, (b) faith in books. (c) faith in the Rasul, and (d) faith in qada and qadar. Religious values related to worship are, (a) public worship, such as helping in the family (b) special worship. Religious values related to morals, namely, (a) morals towards God. (b) the morals of both parents. (c) morals towards oneself (d) morals towards family and relatives. (e) morals towards the community.
\end{abstract}

Keyword: religious values, novels, sociology of literature.

\section{PENDAHULUAN}

Novel bukan hanya sekedar karya fiksi namun juga biasanya merujuk pada jalan kehidupan manusia secara umum. Melalui novel banyak hal yang bisa disampaikan pengarang kepada pembaca. Salah satunya nilai moral yang ada di dalam sebuah cerita yang ingin di bagikan pengarang melalui tokoh-tokoh yang ada di dalam novel. Banyak genre novel di jaman sekarang, seperti genre roman, horror, spiritual dan lain sebagainya dan ada sebagian pengarang yang ingin membuat sebuah karya yang bukan hanya sekedar untuk hiburan tetapi sebuah karya sastra yang berbentuk fiksi yang jalan ceritanya mengandung banyak nilai-nilai kehidupan yang dapat dibagikan kepada pembaca agar bisa menjadi tauladan yang baik dalam berprilaku.

Sebuah karya yang memiliki nilai dan manfaat yang baik adalah karya yang dapat memiliki isi cerita dan tokoh-tokoh yang mencerminkan suri tauladan dalam kehidupannya dalam sebuah cerita. Nilai merupakan landasan seseorang dalam berprilaku dan bertindak di kesehariannya. Nilai juga menjadi batasan seseorang dalam berprilaku. Banyak pengarang fiksi islami menyajikan novel 
yang memberi sentuhan nilai moral melalui jalan cerita yang mengandung nilai-nilai religi agar jalan cerita dapat memberi dampak positif. Terutama pembaca bisa mendalami dan mencontoh nilai religi yang di perankan tokoh-tokoh yang ada dalam novel. Bukan hanya sekedar ingin membagikan karya fiksi saja namun ingin memberikan ilmu agama yang terkandung dalam karya agar menambah pengetahuan pembaca tentang bagaimana berinteraksi dengan sesama manusia dan lingkungan sosial.

Religi seperti sebuah pandangan atau kepercayaan yang cakupannya lebih luas dari diri seseorang dengan tuhannya. Seperti halnya nilai religius yang terdapat dalam sebuah karya sastra. Penulis terkenal seperti Habiburrahman ElShirazy yang sering sekali mengeluarkan novel bergenre fiksi Islami-roman dengan tambahan nilai-nilai religinya begitu banyak penikmat novel yang membacanya. Membuat banyak penulis baru yang bermunculan mengeluarkan karya sastra sejenis novel dengan genre fiksi Islami roman yang menonjolkan kepribadian tokoh yang taat akan agama serta lingkungan yang Islami agar para pembaca bukan hanya sekedar membaca sebuah cerita namun juga bisa memberikan contoh perilaku religi seperti tokoh yang ada dalam karya sastra tersebut.

Nilai religi bukan hanya membahas tentang manusia dengan tuhan namun juga manusia dengan lingkungan dan manusia dengan sesamanya itulah kenapa nilai religi begitu terkait dengan kajian sosiologi sastra yang meneliti tentang sastra sebagai cermin kehidupan. Salah satu novel pengarang asal Kalimantan Selatan yang bernama Noor Ruhaimin berjudul Mengejar Halalnya Syabila sudah dibaca sebanyak 1,7 juta kali dan menjadi peringkat satu untuk cerita dengan tema spiritual di wattpat ini membuat banyak pecinta novel yang tertarik untuk membacanya dalam novel Mengejar Halalnya Syabila karya Noor Ruhaimin ini bercerita tentang seorang gadis berhijab bernama Syabila perempuan tegas dan dingin yang di usia masih muda telah menjadi wanita karir dan seorang laki-laki tampan bernama Ray yang berprofesi sebagai seorang artis. Ray jatuh cinta dengan Syabila berusaha untuk mendapatkan hati Syabila yang begitu sulit untuk dimasuki laki-laki mana pun hingga suatu ketika Ray mengatakan bahwa Dia mencintai Syabila dengan rasa percaya diri ia tidak akan ditolak namun jawaban Syabila membuat Ray takjub.

Syabila mengatakan maaf, kalau kamu mencari seorang pacar, maka jawabanku adalah, aku bukan perempuan yang bisa kamu ajak untuk berpacaran. Dalam hidupku, sebuah hubungan harus diawali dari kata halal. Mendengar ucapan Syabila itu Ray pun membulatkan tekadnya dengan mengejar halalnya Syabila. Banyak sekali nilai religi yang tertuang pada kisah novel Mengejar Halalnya Syabila karya Noor Ruhaimin yang membuat pembaca ingin terus membacanya 
dari awal hingga akhir. Pembaca dibuat takjub dengan prinsip para tokoh dalam memegang teguh kepercayaannya pada nilai agama.

Para peneliti sebelumnya pernah menggunakan pendekatan sosiologi sastra dalam penelitiannya, namun penelitian yang akan dilakukan peneliti sekarang memilikiperbedaanperbedaan. Menindak lanjuti hal tersebut, maka hasil penelitian yang terdahulu dapat digunakan sebagai referensi untuk penelitian saat ini. Judul penelitian yang dilakukan oleh Rosda Liani (2017) ialah Motivasi dan Pesan Religi pada Novel Cinta Dalam Ikhlas Karya Kang Abay (Pendekatan Sosiologi Sastra). Hasil penelitian meliputi dua hal yaitu : (1) motivasi yakni meliputi, (a) keluarga (b) Allah swt. (2) pesan religi meliputi, (a) akhlak kepada Allah (b) akhlak kepada sesama manusia, dan (c) akhlak kepada diri sendiri.

Peneliti tertarik meneliti novel dengan judul Mengejar Halalnya Syabila karena pengarang cerita yaitu Noor Ruhaimin merupakan orang asli Kalimantan Selatan dan berdomisili di kota Banjarbaru mengkaji novel ini salah satu bentuk apresiasi kepada pengarang-pengarang lokal dan karya yang dihasilkan memang sangat bagus bahkan karya fiksi yang dihasilkan memiliki jalan cerita yang mengandung begitu banyak nilai-nilai religi yang ada dalam novel Mengejar Halalnya Syabila karya Noor Ruhaimin. Nilai religi dan hubungan masyarakatyang Islami begitu ditonjolkan pengarang lewat tokoh-tokohnya salah satunya Syabila yang begitu berpegang teguh dengan prinsip hidupnya. Berdasarkan uraian di atas, maka peneliti tertarik untuk melakukan penelitian dengan judul. Nilai Religi dalam Novel Mengejar Halalnya Syabila Karya Noor Ruhaimin. Dengan demikian, tujuan dari penelitian ini adalah untuk mendeskripsikan nilai religi yang berhubungan dengan aqidah dalam novel Mengejar Halalnya Syabila karya Noor Ruhaimin, mendeskripsikan nilai religi yang berhubungan dnegan ibadah dalam novel Mengejar Halalnya Syabila karya Noor Ruhaimin, dan mendeskripsikan nilai religi yang berhubungan dengan akhlak dalam novel Mengejar Halalnya Syabila karya Noor Ruhaimin.

Kajian yang digunakan dalam penelitian ini adalah sosiologi Islam dan menggunakan teori dari sudut pandang Islam karena hubungan nilai religi dengan sosiologi sastra erat kaitannya. Sosiologi sastra adalah penelitian yang terfokus pada masalah manusia karena satra sering mengungkapkan perjuangan umat manusia dalam menentukan masa depannya, berdasarkan imajinasi, perasaan, dan intuisi (Endaswara, 2013: 79). Sosiologi sebagai disiplin ilmu yang mempelajari interaksi manusia yang mencakup ruang lingkup yang luas. Hubungan manusia dengan manusia lain dan apa saja yang dilakukan manusia itu masuk ke dalam ranah analisis sosiologi sastra. 
Selain sebagai disiplin ilmu sosiologi memiliki nilai strategis bagi pengembangan dan penataan kehidupan manusia karena manusia itu makhluk yang tidak bisa hidup sendiri membutuhkan orang lain dan lingkungannya. Manusia yang berkualitas banyak dilihat dari lingkungan dan interaksi sosialnya bukan dengan kesendiriannya. menekankan bahwa dua hal pokok saja, yaitu hubungan dengan Allah (hablumminallah) dan hubungan dengan sesama manusia (hablumminannash) tanpa terjalinnya dua hubungan tersebut dengan baik hidup dan kehidupan manusia terancam sengsara dan hina (Abdussalam, 2014: 26). Aspek sosiologi pada posisi yang sangat sentral dan penting. Kedua setelah hubungan dengan Allah seperti kebanyakan ayat Alquran akan diorientasikan pada dua hubungan tersebut bahkan seperti bentuk ritual khusus yang dilakukan manusia untuk menjalani hubungan antara manusia dengan Allah, seperti shalat, zikir, shaum dan lain sebagainya tetap berkaitan dengan hubungan manusia dengan sesamanya.Dengandemikianapat disimpulkan bahwa sosiologi sastra dalam agama Islam erat kaitannya dengan keimanan seseorang yang dimana iman termasuk dalm unsur-unsur nilai religi yang meliputi akidah, Ibadah dan akhlak.

\section{METODE}

Metode yang digunakan dalam penelitian ini adalah metode deskriptif kualitatif. Teknik pengumpulan datanya menggunakan teknik baca, catat, dan teknik studi pustaka. Adapun data dalam penelitian ini adalah teks-teks, (baik berupa frasa, kalimat, ataupun paragraf yang terdapat dalam Novel Mengejar Halalnya Syabila karya Noor Ruhaimin yang diterbitkan oleh Naa Publisher pada tahun 2018 dengan jumlah halaman sebanyak 259 halaman.

\section{HASIL DAN PEMBAHASAN}

Hasil dan pembahasan data dalam penelitian dilihat sebagai berikut.

\section{A. Analisis Nilai Religi yang berhubungan dengan Aqidah}

Analisis nilai religi aqidah merupakan salah satu unsur pertama nilai religi yang dimana akidah dipahami sebagai ajaran mengenai keimanan. Iman berarti kepercayaan. Kepercayaan adalah keyakinan bahwa sesuatu itu benar adanya tanpa harus dibuktikan dengan metode dan cara. Jika dikembalikan kepada sumber pokok ajaran Islam akidah yaitu keimanan dalam Islam dirumuskan menjadi enam. Berikut uraian nilai religi akidah yang terdapat pada novel Mengejar Halalnya Syabila karya Noor Ruhaimin. 


\section{a. Iman kepada Allah}

Iman kepada Allah ialah rukun iman pertama dalam iman manusia yang dimana iman kepada Allah adalah membenarkan dengan hati, diucapkan dengan lisan dan dibuktikan dengan amal perbuatan. Menjadikan manusia yang beriman kepada Allah memiliki sifat meyakini segala sesuatu dalam hidupnya itu semua kehendak Allah dan memiliki hati yang tentram. Pembahasan yang mengutip tentang iman kepada Allah sebagai berikut.

\section{Data [1]}

"Aisyah bahkan sempat kepikiran karena sangat takut akan kehilangan Syabila sebelum sempat memeluknya. Untungnya dengan mukjizat dari Allah, akhirnya Aisyah dapat melewati masa-masa awal kehamilannya dengan baik dan lancar. (Aqd/ikA,2018:7)

Pada data 1 menunjukkan bahwa Aisyah meyakini dengan sepenuh hati semua masalahnya dapat teratasi karena mukjizat Allah tanpa adanya pertolongan Allah Aisyah tidak akan bisa melewati masa-masa kehamilannya dan melahirkan Syabila dengan selamat.

\section{Data [2]}

"Syabila tak bisa bergerak hanya mengukir seulas senyum dan air mata yang menetes di ujung matanya. Ray melerai pelukannya dan menangkup wajah Syabila. Putri tidurnya telah bangun. "Ya Allah terimakasih karena telah mendengarkan doa-doaku. (Aqd/ikA.2018.231)

Dilihat dari data 2 menunjukkan Ray yang begitu bahagia melihat kesembuhan sang istri Syabila dari koma panjangnya tak henti Ray berterima kasih atas segala yang terjadi dan berakhir dengan baik berkat Allah yang mendengar doa Ray. Ray selalu berprasangka baik pada Allah atas apapun yang terjadi.

\section{b. Iman kepada Kitab-kitab}

Iman kepada kitab berarti iman kepada Allah yang dimana kitab berisi perintah dan larangan, janji dan ancaman, serta nasehat dan petunjuk cara hidup dan beribadah. Beriman pada kitab Allah berarti kita juga yakin bahwa kitab diturunkan oleh Allah bukan buatan manusia dan makhluk lainnya. Semata-mata mempercayai Allah dan meyakini isi serta metauladani isi kitab Alquran itu sendiri menjadi petunjuk hidup dalam mengambil keputusan. Pembahasan mengenai iman kepada kitab terdapat pada kutipan berikut ini .

\section{Data [4]}

"Dengar ya, Dek dalam agama kita itu gak ada yang namanya pacaran dan untuk seumuran Adek kewajibannya adalah belajar. Boleh kita bergaul dengan siapa aja tapi 
harus ingat batasannya dan satu lagi. Berteman harus bisa melihat sisi positif dan negatifnya. (Aqd/ikk.2018:41)

Seperti pada data 4 menunjukkan Syabila yang menasehati adeknya tentang tidak di perbolehkannya berpacaran dalam agama Islam. Perkataan Syabila dibenarkan karena tidak adanya anjuran dalam kitab Alquran berpacaran apa lagi wanita dan laki-laki lawan jenis yang bukan muhrim memiliki hubungan sebelum menikah ada batasan dalam bergaul dan mencari teman.

\section{c. Iman kepada Rasul}

Iman kepada Rasul ialah rukun iman ke empat. Rasul adalah manusia pilihan Allah yang diangkat sebagai utusan dengan tujuan menyampaikan firman-firman Nya kepada umat manusia untuk dijadikan pedoman hidup. Tetaplah beriman kepada Allah dan Rasul-Nya barang siapa yang ingkar kepada Allah, malaikat-Nya, kitab-kitab-Nya , rasul-rasul-Nya maka sungguh orang itu telah tersesat sangat jauh. Pembahasan tentang iman Rasul ada pada kutipan berikut ini.

\section{Data [5]}

"Ray tahu jika kita ingin mendapatkan yang terbaik maka kita harus menjadi orang yang baik pula. Dan Ray berharap dirinya tidak meninggikan rasa sukanya pada Syabila di atas segalanya. Dia akan tetap mencintai Tuhan dan Rasul Nya lebih dari apapun.(Aqd/ikR.2018.90)

Data 5 memperlihatkan tentang Ray yang ingin mendapatkan jodoh yang terbaik dengan cara menjadi orang baik. Namun Ray berusaha untuk tidak menyukai Syabila melebihi rasa sukanya terhadap Allah dan Rasul-Nya itu menyatakan iman kepada Rasul karena Ray mentauladani sifat Rasul yang tidak mencintai manusia melebihi Allah.

\section{d. Iman kepada qada dan qadar}

Takdir atau ketentuan Allah atas hambanya. Mempercayai apa yang terjadi atau sudah terjadi sudah jadi ketentuan Allah atas segalanya. Allah mengetahui segala yang di dunia dan di akhirat tidak ada yang tersembunyi bagi Allah meski itu belum terjadi namun meski segala sesuatu sudah Allah gariskan untuk makhluknya, Manusia juga harus senantiasa berusaha meski Allah mengatur takdir manusia karena segala sesuatu bisa berubah tergantung manusianya itu sendiri, manusia berusaha Allah yang mengatur akhirnya. Pembahasan tentang iman kepada qada dan qadar ada pada kutipan berikut ini.

\section{Data [6]}

"Saat berada di dalam kamar mandi Syabila mengeluarkan alat tes itu dan mencoba. 1 menit... 2 menit... 3 menit.. jantung Syabila seakan berlomba dengan detik yang terus berjalan. "Ya Allah hamba pasrahkan semuanya padamu. (Aqd/ikq,2018: 200) 
Pada data 6 Syabila mencoba untuk memeriksa apakah dia hamil atau tidak berusaha untuk tetap bersabar sambil berharap pada Allah tentang segala sesuatu yang akan terjadi entah itu sesuai dengan apa yang Syabila inginkan atau tidak semua sudah Syabila usahakan tinggal dia berpasrah pada Allah akan segalanya yang terjadi.

\section{B. Analisis Nilai Religi yang berhubungan dengan Ibadah}

Ibadah merupakan unsur kedua dalam nilai religi yaitu, ungkapan rasa syukur manusia kepada tuhan-Nya dan melakukan tugas dengan ikhlas semata-mata untuk mendapatkan ridha Allah ibadah bagian yang sangat penting dari setiap agama. kepercayaan ibadah terbagi menjadi dua yaitu ibadah umum dan ibadah khusus. Berikut uraian nilai religi ibadah yang terdapat pada novel Mengejar Halalnya Syabila karya Noor Ruhaimin.

\section{a. Ibadah Umum}

Ibadah yang jika melakukannya hanya ingin mendapatkan keridhaan Allah biasanya ibadah umum ini jika dilakukan dapat pahala dan jika tidak dilakukan tidak mendapatkan dosa. Ibadah umum biasanya dilakukan pada keseharian manusia seperti, membantu orang tua, membantu sesama, memberi makan hewan. Pembahasan ibadah umum yang terdapat pada kutipan berikut ini.

\section{Data [7]}

"Al Sayang, Bunda minta tolong ambilkan tas Adekdi kamar ya," ucap Syabila sambil memasukan bekal ke dalam tiga buah wadah. Al menuruni tangga dengan membawa tas adiknya dan juga tas yang di sandang di bahu. (Ibd/ibu.2018.251).

Dari data 7 menjelaskan $\mathrm{Al}$ yang membantu bundanya mengambilkan tas adiknya tanpa ada rasa malas atau enggan Al langsung ke atas saat Syabila meminta tolong mencerminkan sifat $\mathrm{Al}$ yang patuh dengan orang tuanya hingga saat disuruh tanpa pikir panjang langsung dilaksanakan.

\section{b. Ibadah Khusus}

\section{Data [8]}

“Ayo kita sholat subuh, Mas imamin ya ?" ucap Ray sambil melepas tangannya dari wajah Syabila. (Ibd/ibK.2018.180)

Kemudian data 8memperlihatkan Ray yang mengajak Syabila yang telah sah menjadi istrinya untuk sholat subuh berjamaah dan Ray menwarkan untuk menjadi imamnya. 


\section{Analisis Nilai Religi yang berhubungan dengan Akhlak}

Akhlak merupakan unsur ketiga dari nilai religi dan unsur terakhir yang dimana nilai religi Akhlak ialah perangai, tingkah laku atau tabiat manusia. Akhlak yang membedakan manusia dnegan hewan tanpa akhlak akan hilang derajat kemanusiaannya sebagai makhluk Allah yang paling mulia. Berikut uraian nilai religi akhlak dalam novel Mengejar Halalnya Syabila karya Noor Ruhaimin.

\section{a. Akhlak terhadap Allah}

Mencintai Allah di atas segalanya bertakwa kepada Allah dengan menjauhi segala larangannya. Akhlak terhadap Allah meliputi : takwa, ikhlas, berbaik sangka, bertawakal, dan memikirkan keindahan ciptaan Allah itu termasuk akhlak terhadap Allah. Pembahasan yang mengutip tentang akhlak terhadap Allah sebagai berikut.

\section{Data[9]}

"lagi-lagi bagai di hantam batu, putri merasa dadanya panas dan kepalanya sakit. Ternyata dia telah salah menyukai seseorang yang ternyata adalah suami orang lain. Putri segera undur diri dan keluar dari ruangan Ray. Hatinya terasa remuk berkepingkeping. Ray sudah mempunyai istri dan akan menjadi seorang ayah."ya Allah maafkan hambamu ini. Batinnya. (Akh/atA.2018.214)

Dilihat dari data 9 Putri yang menyukai Ray terkejut karena Ray telah memiliki istri karena Putri memiliki akhlak yang baik bukannya marah atau bersifat jahat Putri memilih untuk mundur karena tidak sepantasnya Putri menyukai laki-laki yang sudah menikah dan memiliki seorang istri karena itu Putri meminta maaf pada Allah sudah menyukai suami orang walau sebenarnya dari awal Putri tidak mengetahuinya.

\section{b. Akhlak terhadap kedua orang tua}

Akhlak tehadap oraang tua banyak di jelaskan dalam Al quran itu berarti seorang anak haruslah berbuat baik dan menghormati orang tua yang telah mengandung dan membesarkannya. Keridhaan Allah tergantung pada keridhaan kedua orang tua, dan kemurkaan Allah tegantung pula pada kemurkaan kedua orang tua. Akhlak terhadap orang tua seperti menyayangi, berbicara lemah lembut, berprilaku baik dan patuh akan perintah orang tua. Pembahasan tentang akhlak terhadap kedua orang tua terdapat pad kutipan sebagai berikut. 


\section{Data [10]}

"Al bahagia kalau liat Bunda bahagia. Bagi Al Bunda adalah sebuah keajaiban dan melihat bunda berada di tengah-tengah kami sampai saat ini itu sudah lebih dari cukup al sayang banget sama bunda. Syabila meneteskan air matanya. Kalimat syukur selalu dia ucapkan karena sampai saat ini keluarga kecilnya banyak dilimpahi kebahagiaan oleh Allah. (Akh/ato.2018.243)

Terlihat pada data 10 mejelaskan bagaimana Al begitu menyayangi ibunya dan memuliakan Syabila seperti ucapan AL yang begitu bersyukur melihat bundanya yang telah bangun dari koma yang lama dan bisa kembali bersama mereka.

\section{c. Akhlak terhadap diri sendiri}

Perilaku yang baik dari diri sendiri yang mencerminkan manusia yang berakhlak ialah manusia yang meliputi, memelihara kesucian diri, menutup aurat, adil, jujur dalam perkataan, ikhlas, sabar, pemaaf serta rendah hati. Pembahasan tentang akhlak terhadap diri sendiri dapat dilihat dari kutipan berikut.

\section{Data [11]}

"oke cukup." Syabila memeriksa kembali barang bawaanya, merapikan gamis serta hijabnya kemudian segera turun. (Akh/atd.2018.7)

Dari data 11 dapat dilihat Syabila yang berpakaian sesuai dengan Syariat islam tidak terlalu mengedepankan fashion jaman sekarang yang tidak sesuai dengan ketentuan menutup aurat yang benar.

\section{d. Aklak terhadap keluarga dan kerabat}

Berprilaku Saling menyayangi antar keluarga ayah dan ibu, suami dan istri anak dan saudaranya. Saling membina kasih sayang mencintai dan memberi karena Allah swt. Pembahasan akhlak terhadap keluarga dan kerabat dapat dilihat dari kutipan berikut ini.

\section{Data [12]}

e. "Ray tak mau kalah, di bukanya tangan Syabila yang menutupi wajahnya lalu kembali menciumi seluruh wajah Syabila,"Mas lagi bahagia Sayang" di rengkuhnya Syabila ke dalam pelukannya, "terimakasih ya Sayang, ini hadiah terindah yang pernah Mas terima selain kamu. (Akh/atK.2018.201)

Dari data 12 dapat dilihat bagaimana sayangnya Ray kepada Syabila dengan menciumi seluruh wajah sang istri karena rasa bahagia mengetahui kehamilan Syabila tak lupa Ray berterima kasih kepada Syabila. 


\section{Data [13]}

"Saya ingin memberikan kamu sepasang burung ini sebagai pertanda cinta saya sama kamu. Kamu tau Syabila bahwa burung merpati adalah burung yang setia dengan pasangannya, oleh karena itu saya memberikan kamu sepasang burung ini sebagai lambang janji saya sama kamu untuk selalu setia sampai maut yang memisahkan kita. Kamu juga harus tau Syabila bahwa sejauh-jauhnya burung merpati ini terbang maka dia pasti akan kembali lagi pada pasangannya." (Akh/atK.2018.158)

Kemudian terdapat data 13 dilihat Ray yang memberikan Syabila dua burung merpati pada saat acara pertunangan mereka tanda cinta Ray pada Syabila. Ray berujar makna dari dua burung merpati itu agar mereka saling setia karena sejauh apapun merpati terbang dia akan tetap kembali kpada pasangannya.

\section{f. Akhlak terhadap masyarakat}

Berprilaku sesuai dengan norma yang ada dalam masyarakat. Akhlak tehadap masyarakat seperti, memuliakan tamu, menghormati nilai dan norma yang berlaku, menaati putusan dan peraturan yang telah diambil, bermusyawarah dalam segala urusan untuk kepentingan bersama.

\section{Data [14]}

"Ray sangat susah untuk menolak ajakan mereka karena ini juga menyangkut sopan santun Ray sebagai tuan rumah. Akhirnya Ray menyetujui ajakan mereka dan terlihat dari ekspresinya kalau mereka sangat senang Ray bisa bergabung. (Akh/atm.2018.190)

Dilihat pada data 14 menjelaskan bagaimana Ray berusaha untuk menuruti apa yang diingikan para tamu perusaaan yang mengajaknya untuk makan siang. Meskipun tamu Ray semuanya wanita yang terlihat tertarik dengan Ray tetap meiyakan ajakan mereka tapi dengan menjaga jarak karena Ray tetap menjaga diri dan perasaanya untuk istrinya.

\section{SIMPULAN}

Berdasarkan hasil analisis mengenai nilai religi dalam novel Mengejar Halalnya Syabila karya Noor Ruhaimin dari aspek yang diteliti dengan menggunakan kajian sosiologi sastra dapat disimpulkanNilai religi aqidah yang dikemukakan dalam novel Mengejar Halalnya Syabila Karya Noor Ruhaimin ini, terdapat empat nilai yaitu : a. iman kepada Allah, keyakinan Aisyah dan Syabila akan pertolongan Allah di balik semua yang terjadi.b. iman kepada kitab-kitab ,kepercayaan penuh Syabila akan ajaran agama Islam tidak melakukan apa yang memang tidak ada di dalam kitab Alquran. c. iman kepada Rasul, perilaku Ray yang mejadikan Rasul suri tauladan dalam bertindak. 
d. iman kepada qada dan qadar. Menerima segala ketentuan Allah dan berserah diri atas segala cobaan yang dihadapi.

Nilai religi ibadah yang dikemukakan dalam novel Mengejar Halalnya Syabila Karya Noor Ruhaiminini terdapat dua nilai religi ibadah yaitu: a). ibadah umum, tolong-menolong dalam keluarga seperti Al yang membantu bundanya dan Ray yang mendengarkan ceramah di pagi hari. b). ibadah khusus, Syabila yang tidakk meninggalkan kewajiban sholat dimanapun dia berada.

Nilai Religi Akhlak yang dikemukakan dalam novel Mengejar Halalnya Syabila Karya Noor Ruhaiminini terdapat lima nilai yaitu a). akhlak terhadap Allah, mengutamakan Allah diatas segalanya seperti Putri yang memilih menjauhi Ray. b). akhlak terhadap orang tua, Al yang begitu menyayangi Syabila c). akhlak terhadap diri sendiri, berpakaian sesuai dengan Syariat Islam seperti Syabila yang menutup aurat dan menjaga kehormatannya.d). akhlak terhadap keluarga dan kerabat, saling menyayangi antara suami dan istri seperti Ray yang begitu mencintai Syabila.e). akhlak terhadap masyarakat, menghormati tamu seperti Ray yang menyetujui untuk makan bersama tamu perusahaan meski semua tamunya adalah wanita.

\section{SARAN}

Sebagai saran bagi para pembaca berbagai kalangan agar kiranya selalu menjaga akhlak dalam berbagai hal. Akhlak ini jadikan sebagai jati diri yang dijaga dengan baik. Selain itu, jagalah hubungan antarsesama agar terjalin kerukunan dan kebersamaan. Kemudian, apabila ditimpa sebuah masalah maka hadapi dengan tenang dan sabar serta serahkan segala sesuatu dengan Tuhan.

\section{DAFTAR PUSTAKA}

Abdussalam, A. 2014. Teori Sosiologi Islam (kajian sosiologis terhadap konsep-konsep sosiologi dalam Al-Quran Al-Karim). Jurnal Pendidikan Agama islam. (online), vol 12 no 1. http://journal.upi.edu/file/03_-_Teori_Sosiologi_Islam_-_Aam.pdf diakses 30 maret.

Creswell, J. W. 2015. Penelitian Kualitatif \& Desain Riset. Yogyakarta: Pustaka Pelajar.

Endaswara, S. 2013. Metodologi Penelitian Sastra. Yogyakarta: CAPS.

Jumhuru, M. A. A. 2015. Belajar Aqidah Akhlak. Yogyakarta: Budi Utama.

Kusaeri, A. 2008. Akidah Akhlak. Bandung: Grafindo Media Pratama. 
Mannan, K. A., dkk. 2012. Penerapan Teknologi Smart Building pada Perancangan SmartMasjid. (online). Vol 2 no 1 . http://ejournal.uin-malang.ac.id/index.php/ JIA/article/viewFile /2205/ pdf diakses 12 juli.

Ratna, N. K. 2011. Teori, Metode, dan Teknik Penelitian Sastra. Yogyakarta: PUSTAKA PELAJAR.

Ruhaimin, N. 2018. Mengejar Halalnya Syabila. Banyuwanigi:Naa Publisher.

Sabiq, S. 1993. Aqidah Islam (ilmu Tauhid). Bandung: CV Diponegoro.

Sahnan, A. 2018. Konsep Akhlak dalam Islam dan konstribusinya terhadap konseptualisasi Pendidikan dasar Islam. (online). Vol 2 no 2. http://journal.staincurup.ac.id/index.php / JDP/ article/ view/ 658 diakses 12 juli.

Semi, M. A. 2012. Metode Penelitian Sastra. Bandung: CV Angkasa.

Yusuf, M. S. dan Durrah, A.2007. Pustaka Pengetahuan Alquran. Jakarta: PT. Rehal Publika.

Zaidan, dkk. 2007. Kamus Istilah Sastra. Jakarta : Balai Pustaka. 